\title{
A FAVOR DE LA TRANSMISIBILIDAD DE LA ACCIÓN DE DAÑO MORAL
}

\author{
ALFONSO PÉREZ ISLAS \\ Universidad Adolfo Ibáñez
}

\begin{abstract}
RESUMEN: La doctrina y jurisprudencia chilenas se han negado a aceptar la transmisibilidad de la acción de daño moral, e incluso la ven como una posible ilegalidad. Su principal argumento va dirigido a concebir a esta acción como un derecho personalísimo, intransferible e intransmisible en todo aspecto. Para adjudicar dicha calidad, estas posturas entienden que esta acción es personalísima por su propia naturaleza sin necesidad de analizar las normas positivas que rodean esta discusión. Efectivamente, la adjudicación a personalísima es formalmente discutible, pero aún así, existen razones que van más allá de la sola ley que permiten aceptar la transmisibilidad y conciliar las actuales discusiones.
\end{abstract}

Palabras clave: Responsabilidad civil, daño moral, derechos personalísimos, transmisión.

ABSTRACT: Chilean principles and jurisprudence have refused to acknowledge the transfer of moral damage, while also possibly claiming it illegal. The main argument is to recognize moral damage as a personal right, and non-transferable. The establishment of moral damage as personal and non-transferable was based on the understanding that this right is personal by nature, without the requirement of examining positive laws that surround this discussion. Certainly, the attribution of being personal is arguable, but there are reasons that go beyond the law, which allows the transfer and conciliation of actual discussions.

Key words: Civil responsibility, moral damage, personal rights, transfer.

\section{PLANTEAMIENTO DEL PROBLEMA}

En virtud de la gran diversidad de actividades humanas que se llevan a cabo diariamente y, más aún, de la implementación de las máquinas en los diversos procesos productivos, asociado esto a los riesgos del desarrollo y operación de las mismas, es que se ha venido realzando la importancia de la persona humana unida a sus derechos y atributos. Esto ha sido recogido por el derecho civil reflejado en el ámbito de la responsabilidad, donde se ha ampliado la categoría de daños reparables -ya no solo patrimoniales- sino también extrapatrimoniales $y$, particularmente, en orden a reconocer el daño moral.

Así, en un principio, esta situación es reconocible producto de los diversos daños que surgían producto de los tranvías y accidentes ferroviarios, que causaban lesiones a los accidentados e incluso la muerte. Por esta razón, procedían indemnizaciones con el objeto de reparar los daños causados a la víctima o a los deudos. Pero esta indemnización no se refería al daño moral propiamente tal, sino que tenía por objeto reparar el daño provocado ya por la ausencia de la víctima o por la incapacidad sobreviniente de la misma. Entonces se trataba más bien, de una reparación del daño patrimonial.

\footnotetext{
Alumno de quinto año de Licenciatura en Ciencias Jurídicas y Sociales, Universidad Adolfo Ibáñez, Santiago.
} 
Dentro de este marco es que a principios de siglo comienzan a dictarse sentencias que reconocen el daño moral bajo la forma del dolor o aflicción que causa la muerte o las lesiones; de esta manera, ya en 1907, la Corte de Apelaciones de Santiago reconoce el daño moral bajo la idea de sentimiento y valor de afección ${ }^{1}$. Es así como el daño moral se define como una molestia o dolor no patrimonial, en el sufrimiento moral o físico ${ }^{2}$, el cual, en rigor, no lesiona el patrimonio ni se traduce en ninguna pérdida pecuniaria, debido a que el patrimonio de la víctima permanece incólume: se refiere exclusivamente al dolor, pesar o molestia que sufre una persona en su sensibilidad física o en sus sentimientos, creencias o afectos. Debido a esto es que a la indemnización que repara este daño se la ha denominado pretium doloris.

En relación al daño moral propiamente tal, nuestro código no contempló expresamente su indemnización: han sido los tribunales los que la han ido incorporando en base a la redacción del artículo 2329 inciso primero del Código Civil, el cual establece que "por regla general todo daño que pueda imputarse a malicia o negligencia de otra persona, debe ser reparado por esta”, reafirmado, a su vez, por el artículo 2314 del mismo cuerpo, al señalar que “... [quien] ha cometido [un hecho ilícito] que ha inferido daño a otro, es obligado a la indemnización”. En ambos artículos, como fácilmente puédase observar, se habla lisa y llanamente de "daño" y de "todo daño", sin hacer distinción alguna acerca de qué categorías o clases de daños son los que han de ser reparados. Dada esta manifiesta ausencia de especificación, los tribunales nacionales han venido -y de manera progresiva desde los albores del siglo pasado- dando lugar a la resarcibilidad del daño moral, al interpretar ambas disposiciones en su tenor literal.

A su vez, el actual marco constitucional favorece toda interpretación amplificadora de la tutela personal, al consagrar como primera garantía en el artículo 19 numeral primero, el derecho a la vida y a la integridad física y psíquica de la persona y el respeto y protección a la vida privada y pública como a la honra de la persona y su familia en el numeral cuarto, a cuyo respeto están obligados todos los tribunales ${ }^{3}$.

Lo señalado permite reconocer la procedencia del daño moral, con gran auge en los últimos años, puesto que hoy en día no se discute la reparación del daño dentro del ordenamiento jurídico nacional. De este modo se plasma en las actuales prácticas jurídica y jurisprudenciales el principio dirigido al deber de no dañar, ahora también en materia extrapatrimonial.

Así, según lo dispuesto en nuestro Código Civil en su artículo 2314 en relación con el 2284, se entiende que la responsabilidad extracontractual es la que surge de haber cometido un hecho ilícito que causa daño a otro el cual puede derivarse de un delito o cuasidelito civil.

Domínguez Hidalgo, Carmen. El Daño Moral, T. I. Santiago, Chile: Editorial Jurídica de Chile, 2000, p. 33.

2 Alessandri Rodríguez, Arturo. De la Responsabilidad Extracontractual en el Derecho Civil Chileno. Santiago, Chile: Editorial Jurídica de Chile, 1941, p. 220.

3 Domínguez Hidalgo, Carmen, op. cit. (n. 1), p. 360 
Dejando establecida la procedencia, tanto del daño moral como de su posterior indemnización pretium doloris, es menester analizar un aspecto que creemos necesariamente se deriva de tal situación y que se refiere precisamente a la transmisibilidad de la acción por el daño moral sufrido por una persona. Resulta indudable que cuando la indemnización se fundamenta en el daño patrimonial, se seguirían las reglas de la sucesión hereditaria, según lo establecido en el artículo 2315 del Código Civil, al disponer que "puede pedir esta indemnización no solo el que es dueño o poseedor de la cosa que ha sufrido el daño, o su heredero (...)". Tampoco habría mayor espacio para la discusión en el caso que nada se hubiese dicho al respecto, puesto que de igual manera, existiría el derecho a la indemnización ya que el daño, al ser de carácter patrimonial, sería por tanto transmisible pues no existe norma alguna que lo prohíba. A esta conclusión llega René Ramos Pazos, quien sostiene que la acción derivada de un hecho ilícito es transmisible por testamento o ab intestato, a título singular o universal ${ }^{4}$. Pero ante la situación contraria, la víctima afectada por un hecho que causa un daño moral en ella, tiene la acción para reclamar su reparación y en el caso que la víctima falleciese habiendo ejercitado la acción ante tribunal competente, no cabe duda que sus herederos podrán continuarla, siguiendo lo dispuesto en el artículo 5 del Código de Procedimiento Civil, que dispone "si durante el juicio fallece alguna de las partes que obre por sí misma, quedará suspenso por este hecho el procedimiento, y se pondrá su estado en noticia de los herederos para que comparezcan a hacer uso de su derecho en un plazo igual al de emplazamiento para contestar demandas, que conceden los artículos 258 y $259 "$.

De esta manera, parece claro que pueden reclamar la indemnización por daño moral tanto la víctima del hecho dañoso como sus herederos, en el caso que la víctima falleciese durante la substanciación del proceso ante tribunal competente.

Por otro lado, aquellos que hayan sufrido un daño de esta naturaleza, dado el vínculo que mantienen con la víctima, también tienen derecho a ser indemnizados, según han dispuesto nuestros tribunales de justicia:

“(...) tratándose de daño moral, pueden demandar su reparación la víctima inmediata o directa, esto es, la persona misma en quien recae la lesión, ofensa o injuria que lo causa, y los que sin tener esa calidad también lo sufren en razón de que el daño inferido a aquellas los hiera en sus propios sentimientos o afectos, incluso aun cuando no sean sus herederos o parientes" 5 .

\footnotetext{
Ramos Pazos, René. De la Responsabilidad Extracontractual -3a edición- Santiago, Chile: LexisNexis, 2006, p. 110

Sentencia del $2^{\circ}$ Juzgado de Concepción, confirmada en queja por Corte. Suprema., 15 de diciembre de 1983, en: Revista de Derecho y Jurisprudencia, t. LXXX, sec. 1ª, p. 128
} 
De lo resuelto se desprende, por tanto, que las víctimas indirectas pueden demandar -incluso- conjuntamente con la víctima inmediata la indemnización del daño moral, por concepto del perjuicio sufrido por "rebote" o "repercusión".

Recapitulando, respecto de la transmisibilidad de la acción de daño moral, es posible plantear tres hipótesis. La primera se plantea en el caso que la víctima fallece habiendo deducido la acción procesal pero sin que se haya dictado sentencia en el respectivo procedimiento, es decir, permaneciendo la "litis pendencia". No se deduce de esto un conflicto ya que, según las reglas generales del procedimiento civil, el proceso continuará sin importar la muerte del demandante, por sus herederos.

La segunda de ellas está ligada a la situación en que la víctima fallece cuando ya hay sentencia que acoge la demanda por el daño moral sufrido. Esta situación no plantea mayores reparos, debido a que la acción ejecutiva para cobrar la indemnización se transmitiría a sus herederos, según se desprende del Código Civil en su artículo 1097.

La tercera y última hipótesis es, precisamente, la que presenta mayor complejidad, debido a que en este caso, la víctima muere antes de deducir la acción procesal, por lo tanto, cabe preguntarse ¿pueden sus herederos demandar la indemnización por el daño moral sufrido por la víctima directa del hecho ilícito?

En principio, la mayor parte de la doctrina y nuestros tribunales ${ }^{6}$ a la fecha, niegan la posibilidad de la transmisibilidad de la acción en un caso así. No obstante a nuestro juicio, creemos posible justificar la tesis contraria, vale decir, que se ajusta a derecho la transmisibilidad de la acción de indemnización por daño moral, por las razones que pasaremos a exponer.

\section{CARÁCTER PERSONALÍSIMO DE LA ACCIÓN DE REPARACIÓN POR DAÑO MORAL}

El daño moral, como se ha afirmado en forma reiterada por parte importante de la doctrina nacional, es el sufrimiento de carácter espiritual, físico o psíquico que perjudica a una persona ${ }^{7}$ y que no puede ser determinado por elementos estrictamente económicos. El

\footnotetext{
6 Así lo confirman las sentencias de la Corte Suprema de fecha 27 de junio de 2007, Rol civil Nº 309-06 y noviembre de 2007, Rol No 6196-2006, esta última en su considerando cuarto: "acerca de la transmisibilidad del derecho a demandar indemnización de perjuicios alegada por la actora cabe tener presente en primer lugar que, como se encuentra acreditado en autos don Emilio Nualart Pino solo sobrevivió con cierto grado de conciencia algunos segundos; en segundo lugar, que el derecho a pedir indemnización de perjuicios por daños extrapatrimoniales es personalísimo y no se comprende dentro de aquellos que el de cujus (sic) puede transmitir por herencia; y en tercer lugar y a mayor abundamiento, que no puede presumirse que el herido hubiese pensado en tal acción judicial reparatoria en el brevísimo tiempo en que estuvo consciente, lapso en el cual ciertamente nada manifestó al efecto. Sostener lo contrario, según la mayor parte de la doctrina sería aceptar la existencia de una ganancia sin causa ya que la acción nace a consecuencia del hecho ilícito es decir cuando el daño ya se ha producido y en ese momento ya no existe el posible titular o, como en el caso de autos, está totalmente privado de conciencia”.

7 En este sentido, por citar algunos ejemplos: ALESSANDRI RODRíGUEZ, Arturo, op. cit. (n. 2), p. 220; RodríGUEZ GrEZ,
} 
perjuicio al cual está afecta una persona, evidentemente, no tiene un carácter abstracto ni difuso, de manera tal que no pueda objetarse su pertenencia a un sujeto o a varios. Es por esto que el daño moral sufrido debe analizarse en concreto y, desde esta perspectiva, es pertinente que el detrimento que acongoja a la víctima, no puede pertenecer sino a él y a nadie más; en otras palabras, solo es reconocible que el sufrimiento causado a alguien, lo corre dicha persona por cuenta propia y así lo ha entendido tradicionalmente por la doctrina ${ }^{8}$. Como se mencionó anteriormente y siguiendo el mismo razonamiento, el hecho dañoso del cual es víctima una persona puede llegar incluso a afectar a terceros que, dado un especial vínculo o relación determinada han visto en el sufrimiento de la primera un dolor similar que les puede llegar a causar un perjuicio a las segundas ${ }^{9}$, pero de cualquier manera, este perjuicio "reflejo" no obsta al carácter concreto en que se debe apreciar el daño moral, puesto que si bien proviene justamente de un dolor ajeno, el daño sufrido por los últimos es uno por completo distinto y pertenece total y exclusivamente a estos. Creemos entonces que el menoscabo extrapatrimonial sufrido por una persona, es personalísimo de esta. Derivado de este daño, se ha entendido que quien es víctima de tales menoscabos tiene a su haber una acción contra el patrimonio de los responsables para que, de este modo satisfaga su crédito como cualquier acreedor contra un deudor.

Sin embargo, se ha aludido que este efecto personalísimo del daño experimentado se expandiría incluso a la acción indemnizatoria que busca compensar dicho perjuicio y que como tal, no sería bajo ningún aspecto transmisible ${ }^{10}$. Los autores proclives a afirmar esta intransmisibilidad, basan su argumento en que los derechos personalísimos lo son únicamente por la calidad inherente de su naturaleza, que de alguna forma se "explican a sí mismos" como derechos inherentes a la personalidad humana; un ejemplo de ello sería que no existe norma alguna positiva en Chile que establezca el carácter intransmisible para los derechos sobre el propio cuerpo, pero es indudable que es personalísimo y nadie podría objetarlo por su propia particularidad. Si bien en casos como el descrito parece evidente la propiedad personalísima de estos derechos, no creemos que sea así como deba discernirse la calidad de estas facultades. El legislador civil ha establecido normas positivas sobre la cual es posible adscribir o no las idoneidades mencionadas y, teniendo esto en cuenta, no correspondería usar únicamente un criterio de presunción por (aparente) obviedad.

Pablo. Responsabilidad extracontractual. Santiago, Chile: Editorial Jurídica de Chile, 1999, p. 311; DiEZ SCHWERTER, José. El daño extracontractual. Santiago, Chile: Editorial Jurídica de Chile, 1997, p. 82.

8 Alessandri Rodríguez, Arturo, op. cit. (n. 2), p. 36.

9 Elorriaga De Bonis, Fabián. Novedades judiciales en torno al daño moral por repercusión. En: Estudios de Derecho Civil II. Santiago, Chile: LexisNexis, 2007, pp. 297-321; AlESSANDRI RODRÍGUEZ, Arturo, op. cit. (n. 2), pp. 475 y 463 ; BARROS BOURIE, Enrique. Tratado de responsabilidad extracontractual. Santiago: Editorial Jurídica de Chile, 2006, pp. 345 a 365.

10 Barros Bourie, Enrique, op. cit. (n. 9), pp. 945-946; Domínguez ÁGuila, Ramón. "Sobre la transmisibilidad de la acción por daño moral”, en: Revista Chilena de Derecho, vol. 31, N 3. Santiago, Chile: Pontificia Universidad Católica de Chile, 2004, pp. 508-513. 
Por lo tanto, es posible objetar la tesis contraria usando argumentos formales. En nuestro Derecho Civil está establecida como regla general la "transmisibilidad de todos los derechos y obligaciones del causante a sus herederos"11 y que los derechos personalísimos son, en definitiva, una excepción a esa regla. En efecto, nuestro Código Civil ha establecido la intransmisibilidad de -al menos- seis acciones por tratarlas como personalísimas: derechos de adjudicación preferente (art. $1337 \mathrm{~N}^{\circ} 10$ ), derecho de alimentos (art. 819), derecho de uso y habitación (ídem), asignación de prestaciones periódicas (art. 1087), derechos de usufructo y la acción de revocación de donación, mientras que en un orden no patrimonial podemos encontrar los derechos que forman el contenido de la personalidad y además los inherentes al estado y capacidad de las personas y también los demás derechos de familia ${ }^{12}$. Dicho sea de paso, no existe duda alguna que en todos aquellos derechos se concentra un rol patrimonial que se pretende resguardar y, por lo tanto, subsistiría su comerciabilidad por lo que son susceptibles de dominio y posesión por los particulares, no obstante se ha establecido respecto de ellos su inalienabilidad ${ }^{13} \mathrm{y}$, por ende, su respectiva intransferencia e intransmisibilidad.

Ahora bien, respecto de la acción sobre la cual se ha planteado la duda, creemos que la posibilidad de ser personalísima y consecuentemente adquirir las características comunes de estas, no puede concurrir sino por medio de una regulación especial impuesta por ley determinada. El legislador, al haber establecido como principio del Derecho Sucesorio la transmisibilidad de todos los derechos y obligaciones a sus sucesores, no puede haber hecho otra cosa sino que instaurar expresas excepciones al establecer a aquellos derechos, como personalísimos. El entender que la acción en comento adquiere la calidad de derecho personalísimo, sería concebir que se está aplicando un razonamiento por analogía para investir de esta calidad a un sujeto que, a priori, no la posee. Dicha analogía jurídica sería de suyo equívoca ya que la esencia misma de interpretar bajo estos estándares, viene dada por la necesidad de cubrir "lagunas legales" mediante un método de integración de la ley ad-hoc ${ }^{14}$, usando como herramientas a otras normas similares a aquella que posee un vacío. Luego, sería incorrecto aseverar que la analogía tiene lugar en esta situación, ya que no puede afirmarse tajantemente que exista una falta de regulación expresa, acerca del carácter intransmisible o personalísimo de la acción de daño moral (como si efectivamente existiese una laguna legal), puesto que di-

\footnotetext{
1 Somarriva Undurraga, Manuel. Derecho sucesorio -3ra edición- Santiago, Chile: Editorial Jurídica de Chile, 1981, pp. 20-21; RAMOS PAZOS, René. Sucesión por causa de muerte- Santiago, Chile: Editorial Jurídica de Chile, 2008, p. 10; TrONCOSO Larronde, Hernán. Derecho sucesorio - 4a edición- Concepción, Chile: LexisNexis, 2006, pp. 14-15.

12 Alessandri R., Arturo, Somarriva U., Manuel y Vodanovic H., Antonio. Tratado de Derecho Civil -6ta edición- Santiago, Chile: Editorial Jurídica de Chile, 1998, t. 1 N 455, pp. 316-317.

13 VIAL DEL Río, Víctor. Teoría general del acto jurídico -5a edición- Santiago, Chile: Editorial Jurídica de Chile, 2003, N 119 , p. 177.

14 SQuella Narducci, Agustín. Introducción al Derecho. Santiago, Chile: Editorial Jurídica de Chile, 2004, pp. 485-489.
} 
cha norma ya existe y la hemos mencionado: el principio general es que el causante sucede en todos sus derechos y obligaciones, con contadas excepciones a las que hemos hecho alusión.

De esta manera, puede sostenerse que mientras la ley no disponga expresamente que esta acción cae dentro de los derechos personalísimos, no tendría por qué considerarse lo contrario, so pena de redundar en discusiones análogas, pongamos por caso, a la concurrencia o no de la inexistencia y de la nulidad absoluta para determinados $\operatorname{casos}^{15}$.

\subsection{RAZONES GENERALES}

A mayor abundamiento, y apelando al principio de no contradicción, es menester hacer presente que, como regla general en derecho privado -no solo en materia contractual, sino que de modo transversal al derecho privado-, está permitido todo lo que no está expresamente prohibido. En otras palabras, siendo la regla general que todos los derechos y obligaciones son transmisibles y en la medida que el Código Civil dispone expresas excepciones, entre las cuales no está la intransmisibilidad de la acción de indemnización por daño moral ${ }^{16}$, no parece irrazonable afirmar que la transmisibilidad de dicha acción se ajusta a derecho.

Por otra parte, la acción que se dirige a la reparación de los daños morales, constituiría un crédito desde el momento mismo de la producción del daño a causa del eventus damni, y es precisamente en ese momento en que se produce la lesión susceptible de apreciación pecuniaria y la posibilidad de demandarse su reparación -en rigor, su compensación-. En la medida que ingresa un crédito en el patrimonio de la víctima, es decir, un derecho a obtener una compensación pecuniaria del autor del hecho ilícito, deviene en un derecho patrimonial perfectamente transmisible, puesto que, como señalamos reiteradamente, la ley no expresa prohibición alguna sobre su transmisibilidad.

Acerca de esto, consideramos necesario hacer presentes ciertas distinciones de no menor importancia a efectos de aportar mayor claridad a lo recién señalado: una cosa es la lesión de un derecho personalísimo y otra es el crédito que nace a causa de esa lesión. En la inevitable progresión lógica, también hay que distinguir entre la existencia de dicho crédito y el reconocimiento que haga un tribunal de tal derecho, puesto que, en el caso que un tribunal no acoja una demanda de indemnización por daño moral, tal rechazo no significa que la obligación de compensar el daño no exista o que se extinga por la sentencia judicial, conforme a los dispuesto por el artículo 1471, en relación al numeral cuarto del artículo 1470 la obligación

\footnotetext{
15 Vial DEL Río, Víctor, op. cit. (n. 13), pp. 237-248. Al igual que en el conflicto que hemos planteado, la discusión acerca de estas sanciones civiles (nulidad e inexistencia) rebosa en la única necesidad de haber consagrado la inexistencia de manera expresamente legal o no.

16 Evidentemente no lo está, puesto que la misma responsabilidad por daño moral no está consagrada expresamente en dicho cuerpo legal, sino que es, como se mencionó con anterioridad, una creación jurisprudencial basada en una interpretación cuyo eje es el elemento gramatical de los artículos 2329 y 2314.
} 
subsiste, pero la sentencia que desecha la acción de indemnización impide exigir su cumplimiento. Por lo tanto, se hace evidente que el crédito que nace por daño moral sufrido a causa de un hecho ilícito que haya producido un daño, ingresa en el patrimonio de la misma forma en que lo hace la correlativa obligación en el patrimonio de quien comete aquel hecho dañoso. Si a posteriori, la víctima demanda en tribunales el cumplimiento de la obligación, de la misma forma que un acreedor sustentado en un crédito, demanda el cumplimiento de una prestación debida por su deudor, y será una cuestión diversa al origen que le da nacimiento a su crédito, ya que este habrá existido independiente de la dictación de una sentencia que lo reconozca llanamente.

Por otro lado, parte de la doctrina plantea una comprensión diversa a la exclusiva visión del daño moral como pretium doloris. En efecto, algunos autores entienden el daño moral como una lesión a intereses extrapatrimoniales ${ }^{17}$. Desde una comprensión tal, se amplían enormemente las perspectivas en dirección a aceptar la pertinencia de la transmisibilidad de la acción de daño moral, sino a todo evento, al menos a un mayor número de hipótesis en que la transmisión de dicha acción pueda presentarse. Esto porque entender el daño moral como una lesión a intereses extrapatrimoniales no restringe esta clase de daño al pretium doloris, sino que abarca un campo de aplicación conceptual (y consecuentemente jurisprudencial) mucho mayor, marco en el cual el pretium doloris es una especie más del género daño moral. A modo de simple ejemplo, Alessandri señala que para el caso específico en que la víctima directa del delito o cuasidelito civil muera de inmediato a causa de la comisión del hecho ilícito, no alcanzaría a sufrir perjuicio alguno -más aún, puede que ni siquiera alcance a tener siquiera, un destello de conciencia del daño que sufre- y no habría menoscabo alguno que indemnizar y ningún crédito que alcance a ingresar en su patrimonio, por ende, nada que transmitir a sus herederos ${ }^{18}$. Lo anterior, naturalmente, si se considera el daño moral como mero pretium doloris. Sin embargo, si ampliamos la concepción de daño moral en los términos mencionados, resultaría que la pérdida de la vida de la víctima del hecho ilícito lesiona, en efecto, un interés extrapatrimonial aunque la víctima no experimente nada en su subjetividad ni dolor alguno por una fracción de segundo.

\section{FINALIDAD DE LA REPARACIÓN}

Como expusimos anteriormente, respecto a la finalidad y real aplicación de la reparación de los perjuicios, se puede afirmar que la acción que tiende a la indemnización de los daños extrapatrimoniales dentro de la responsabilidad aquiliana, es por completo asimilable

17 Diez SHWERTER, José, op. cit. (n. 7), pp. 88 y ss.

18 Alessandri RodrígueZ, Arturo, op. cit. (n. 2), p. 380 y ss. 
a la que tiende a la reparación de los daños patrimoniales. Sostenemos que la principal diferencia entre ambas indemnizaciones radica en su capacidad de ser cuantificados (sin restar importancia a la calidad fáctica y subjetiva de una y otra en su origen); por ello, si bien ambos se distinguen secundariamente entre ellas por el hecho que las motiva, la solución es equivalente. Por una parte, los daños patrimoniales se indemnizan aplicando criterios -en principio- más certeros que los aplicables a la determinación de la cuantía de la indemnización por daño extrapatrimonial, cuales son el daño emergente y el lucro cesante, por lo que se puede percibir una reparación más cierta y menos sujeta a la subjetividad del tribunal, de los daños causados.

Por otra parte, los daños extrapatrimoniales son imposibles de ponderar con semejante exactitud, lo que no obsta a que sean igualmente cuantificables, aunque dicha labor quede sujeta a la prudencia del juez que haciendo uso de su criterio -apoyado de elementos reales adscritos a las circunstancias generadoras del daño- determina, finalmente, el monto destinado a resarcir los perjuicios. De esta manera podemos colegir que el fin de la indemnización de la responsabilidad extracontractual, es similar en uno y otro caso.

Sobre la función que cumplen estas indemnizaciones, se ha dicho que la del daño moral solo puede pretender ser compensatoria ${ }^{19}$ o satisfactiva ${ }^{20}$, puesto que dadas las características del bien lesionado, que apuntan a elementos muy abstractos y diversos (dependiendo del sujeto), la víctima nunca va a poder ser indemnizada bajo parámetros tan objetivos como su símil en materia de daños patrimoniales. Sin ánimo de contradecir estas opiniones, podemos sostener que, a pesar de dichas diferentes calidades estas no obstan a lo que en verdad se practica: se llega a una solución económica comparable a la del daño patrimonial, en tanto la forma en que se indemniza el daño extrapatrimonial, es como si este fuese el primero. Esto último se traduce a su vez en que a los ojos del juez, ese daño debe considerarse reparado de la misma forma que si fuera uno patrimonial, ya que en caso contrario, siempre estaría la posibilidad de objetar las decisiones judiciales aludiendo a que de un modo u otro faltó "un tanto más o un tanto menos" de indemnización, debido a que no satisfizo el interés particular de las partes, lo cual evidentemente es inaceptable por razones de seguridad jurídica.

Por estas consideraciones es que los dos tipos de indemnizaciones se manifiestan de forma idéntica (en la práctica), sin perjuicio de sus diversas calidades y características, por lo que pueden ser a este respecto asimilables en su totalidad.

\footnotetext{
$19 \mathrm{Al}$ respecto, la mayoría de nuestra doctrina se encuentra conteste.

20 Rodríguez GreZ, Pablo, op. cit. (n. 7), p. 313. Este autor sostiene que es un error conceptual hablar de indemnización compensatoria, "'más nunca el dolor, indignidad, temor, etc. podrán ser avaluados en dinero". Sin embargo, el producto final no difiere de lo que se sostiene comúnmente al hablar de indemnización compensatoria.
} 


\section{PRINCIPIO DE PROPORCIONALIDAD}

Teniendo por probados los anteriores acápites argumentativos, es menester referirse a los fundamentos que van más allá del solo estudio del Derecho que también debaten acerca de la aceptabilidad legal de la transmisibilidad de este tipo de acción.

Se ha aseverado que la transmisibilidad de daño moral surge debido a una "mercantilización exagerada de la responsabilidad civil" 2122 . Creemos que tal opinión resalta las actuales maniobras judiciales que tienden a restringir en buena medida el cobro de indemnizaciones. Esta corriente, presente hoy en nuestros tribunales y en la doctrina, tiene su origen en un modo de contrarrestar una práctica anterior consistente en la tendencia a indemnizar todo. No hace mucho, se sostenía la idea que prácticamente cualquier daño debía ser reparado, llegando incluso a absurdos ${ }^{23}$. Esta tendencia pronto se hizo evidente, por lo que se llegó a considerar que se podía hacer tan mal uso de la responsabilidad civil, como para llegar a buscar dinero a los tribunales por cualquier razón aparente -algo así como una "lotería judicial"-. Todo esto influyó en que gradualmente se fueran restringiendo las indemnizaciones por responsabilidad, llegando a una concepción actual opuesta a lo que se entendió en un principio: acortar en una buena medida las posibilidades de obtener reparaciones pecuniarias. Asumiendo el flujo de estas corrientes, es comprensible el actual rechazo que de la doctrina y la jurisprudencia tienen en relación a no admitir la transmisibilidad de acciones como la defendida en el presente trabajo. Aceptarla, para la visión actual, sería un modo de justificar una vez más los afanes de riqueza de los particulares, que solo están escudriñando diversas opciones o resquicios para obtener provecho económico.

No podemos sino aceptar que este panorama es perfectamente posible e incluso, actualmente puede ser frecuente su ocurrencia. Sin embargo, también puede considerarse que los detractores de nuestra posición han obviado el hecho de que tales ambiciones - tan mal vistas- son producto de la desproporción que se ha manifestado de manera general en el sis-

\footnotetext{
1 Domínguez ÁGuila, Ramón, op. cit. (n. 10), p. 513

22 Sobre este tema: Vergara BenZANilla, José. "La mercantilización del daño moral". En: Revista Actualidad Jurídica. Santiago, Chile: Universidad del Desarrollo, 2000, pp. 177-189. En este artículo, el autor se dedica a nombrar lo que a su parecer son las principales causas que motivan un afán de lucro desmedido en relación al daño moral y sus indemnizaciones. Sin embargo, nos deja la sensación que en verdad otorga razones para encontrar inadmisible o al menos de manera excesivamente restringida, cualquier tipo de indemnización por concepto de daño moral.

23 Y así por ejemplo tenemos casos que, si bien no han ocurrido en nuestro país, han pasado a ser reconocidas como curiosidades jurídicas. Conocido es el caso en Estados Unidos, en que una abuela demandó a una empresa de microondas por no prevenir en sus instrucciones los perjuicios que traería meter al gato para secarlo <http://federacionuniversitaria10.blogspot. com/2008/04/sentencias-curiosas.html>; o aquel en que un ciudadano pidió una millonaria indemnización en contra de conocidos magos, bajo la excusa que ellos lo hacían ver mal, puesto que él era Dios. "El insólito extremo extracontractual en Estados Unidos: La contaminación del sistema de responsabilidad”, de PINTO LÓPEZ, Francisco, <http://www.publiuris.blogspot.com>. En relación a los casos nacionales, podríamos citar varios en que al parecer y en principio, de un caso menor, se suscitaban indemnizaciones exorbitantemente millonarias.
} 
tema jurídico de la responsabilidad: nos referimos a que no existe concretamente un principio de proporcionalidad que resguarde una justa reparación, sin que se caiga en situaciones disconformes o en absurdos.

Si bien es cierto que el principio que regula la evaluación del daño extrapatrimonial es el de la evaluación prudencial del juzgador ${ }^{24}$, se extraña un método que complemente esta actividad. Por ello, el uso de un principio como el mencionado dentro de la apreciación del juez e incluso la procedencia procesal de demandas indemnizatorias, parece de suyo necesario. A modo de ejemplo, sería pertinente restringir las acciones que pretendan demandar el perjuicio ajeno transmitido y el propio reflejo, a una sola demanda en donde sea solo uno el precio destinado a resarcir ambos perjuicios; permitir su procedencia como dos acciones procesales distintas, efectivamente podría ser causa de desproporciones y, en consecuencia, representar una búsqueda de riqueza más que de compensación. De igual forma, aunque con un mayor esfuerzo, parecería razonable que el legislador regulara la apreciación de daños extrapatrimoniales ${ }^{25}$, de manera tal de salvar los naturales escollos que plantea la incertidumbre de la apreciación de estos menoscabos. Lo que se debiera intentar es de erigir estándares sólidos, de donde el juez pueda desprender una decisión mucho más uniforme con respecto a una indemnización equitativa y así evitar incongruencias e inequidades jurisprudenciales. Evidentemente, no es objeto de este trabajo elucubrar las distintas hipótesis sobre las cuales el principio de proporcionalidad debiera aplicarse; sin embargo es apropiado mencionar su utilidad práctica.

El fuerte resguardo a un principio de proporcionalidad que esté presente en esta materia, permitiría estimar la transmisibilidad de la acción de daño moral como menos dañina de lo que se piensa actualmente. En efecto, se reduciría en grado no menor la posibilidad efectiva de utilizarla como herramienta para alimentar la codicia que moviliza a algunos. A su vez, alivianaría el resto de los inconvenientes que conlleva la apreciación y resarcimiento de perjuicios difíciles de catalogar dentro del derecho de daños y de responsabilidad civil.

\section{SITUACIÓN DEL DAÑO REFLEJO}

El daño reflejo es aquel que padecen las personas que poseen un vínculo de afectividad y cercanía con la persona que sufre directamente el daño de carácter patrimonial o moral producto de una lesión o incluso de su muerte. Una noción más precisa del concepto -muy

24 Domínguez Hidalgo, Carmen. "Hacia una uniformidad y trasparencia de la fijación del quantum Indemnizatorio". En Estudios de Derecho Civil II. Santiago, Chile: LexisNexis, 2007, pp. 278-285.

25 Por supuesto, sin llegar a los casos paradigmáticos de Estados Unidos, donde cada parte del cuerpo y, en definitiva, la vida misma de un ser humano tiene un precio exacto resarcible. Llegar a este punto sería llevar el principio de proporcionalidad a límites inaceptables, transformado contrariamente su finalidad en uno que tienda a la inequidad y desigualdad. 
utilizada por la doctrina- entiende que el daño moral reflejo o por repercusión es "el sufrido por víctimas mediatas de un hecho que ha causado la muerte o lesiones a otra persona" ${ }^{26}$. En otras palabras, las víctimas por repercusión o lesionados indirectos son aquellos que reciben un daño, no directamente en su persona o bienes, sino por sufrir ellos a consecuencia de un daño causado a una persona con la cual tienen una relación ${ }^{27}$.

Con respecto a la acción que toca por la invocación del daño reflejo, cabe señalar que esta es una de carácter personal, puesto que la fundamentación que sostiene la procedencia de esta acción no es el sufrimiento de la víctima inmediata, sino aquel dolor, menoscabo, sufrimiento que se padece por el daño que la mediata experimentó en su propia persona y en virtud de un vínculo que lo liga con la segunda; por lo tanto, su acción es diversa de la que tiene el afectado primario.

No obstante, habría que distinguir si el afectado directo ha muerto o no en el suceso que le causó el daño. Si es que falleció en el hecho, los sucesores tienen la acción transmitida por la víctima inmediata para reparar los perjuicios que esta ha sufrido. Como mencionamos, la transmisibilidad de la acción por daño moral presenta varías diferencias con respecto a la acción por daño reflejo antes sometida a análisis, lo que las hace muy diferentes a una y otra. En el daño reflejo, vemos que el fundamento de su interposición se encuentra en el hecho del menoscabo que a terceros les provoca el perjuicio ajeno, con la cual aquellos tienen una relación. Estos terceros soportan un sufrimiento derivado del daño que esa persona sufre, por lo cual se les reconoce el derecho a demandar por sus propios perjuicios. En el caso de la transmisibilidad de la acción por daño moral, el fundamento no es un sufrimiento propio de estos terceros que ejercen esa acción, sino que esta nace por el daño moral sufrido directamente por una persona determinada. Inhibiendo la calidad de personalísima, la acción por daño moral se puede transmitir a otros con los cuales el titular de esta tenga una vinculación mortiis causa. En definitiva, tendrán la transmisión de la acción a su favor los sucesores por causa de muerte de quién sufrió directamente el daño, incluida la acción refleja.

\subsection{ENRIQUECIMIENTO SIN CAUSA}

En relación al caso concreto en que la víctima falleciese producto del hecho ilícito que genera el daño y en concordancia con lo planteado hasta este momento, a nuestro juicio no es posible que se configure enriquecimiento injusto, puesto que en rigor no habría una doble indemnización por el mismo hecho. Esto porque, en primer lugar, se estaría indemnizando el

26 Barros Bourie, Enrique, op. cit. (n. 9), n² 224, p. 345; Otras concepciones similares en: Alessandri RodríGUEZ, Arturo, op. cit. (n. 2), pp. 457 y 463; RodríGUeZ GreZ, Pablo, op. cit. (n. 7), p. 360. Elorriaga DE Bonis, Fabián, op. cit (n. 9). p. 297.

27 Corral Talciani, Hernán. Lecciones de responsabilidad civil extracontractual. Santiago, Chile: Editorial Jurídica de Chile, 2003, p. 318. 
daño moral sufrido por la víctima directa lo que sin duda es un daño reconocido y que debe ser indemnizado; en segundo lugar, se está reconociendo el llamado daño por rebote que, como fue mencionado, corresponde a los lesionados indirectos que reciben un daño producto del mal o sufrimiento inferido a la víctima. Desde luego, la muerte de una persona puede causar a otros variados perjuicios no patrimoniales que no quedan reducidos al pretium doloris ${ }^{28}$.

En correspondencia a lo expuesto, no se produciría una doble indemnización, puesto que, si bien ambas proceden por el mismo o los mismos hechos, el eventus damni causa daños diferentes a personas distintas, a la víctima directa y a las indirectas, dada la relación previa que vinculaba a las últimas con la primera, como expondremos a continuación.

\section{CONCLUSIONES}

El Código Civil no contempla una indemnización expresa o regulada del daño moral, por lo que con mayor razón tenemos escazas pistas acerca de su transmisibilidad; hemos de saber que el argumento de mayor peso para aceptarla, ha sido que la acción no es concretamente personalísima y también que en derecho privado, al poder hacerse todo lo que no está prohibido $-y$ en vista de que no existe norma que lo prohíba-, cabría aceptarla. No es que podamos aseverar que procede en todos los casos y en todas las circunstancias, pero sí podemos decir que no hay razón para excluirla de manera generalizada.

En algunas legislaciones se prohíbe o se acepta expresamente, como en la española y alemana en que se permitió, de manera reglada y original a principios de los años noventa del siglo pasado ${ }^{29}$, y sin embargo la omisión de este asunto en materia civil (en Chile) pareciera hacer procedente su cabida. Por otra parte, es fundamental considerar como argumento que dejar inoperante la posibilidad de los herederos de ejercer la acción por daño moral del causante, fallecido por causa del daño, significaría un enriquecimiento injusto por parte del que generó aquel deterioro, pues él tendría en su patrimonio una deuda para con el que sufrió daño moral en este caso, obligación que se habría visto extinguida por el hecho de fallecer la persona a la que debía compensar. Pero esto a su vez significaría indirectamente un incentivo - sin considerar las consecuencias penales- para quien daña, pues la muerte figura no solventar dicho crédito y a contrario sensu, “dejarlo vivo” puede significar aún más gastos (imagine usted, por ejemplo, un atropello vehicular).

Incuestionablemente esta es una cuestión que requiere de mucha más discusión. La idea de reformar nuestra legislación reparatoria de daños, incluyendo pautas objetivas para el

28 Domínguez Hidalgo, Carmen, op. cit. (n. 1). Tomo II, p. 737.

29 Sainz Moreno, Fernando. "Transmisión hereditaria de la indemnización por daños morales”, en Revista de Administración Pública. No 124, enero-abril. España: 1991, pp. 445- 457. 
juez resolver de manera más equitativa, es una pretensión osada, pero solventaría varias trabas legales, entre ellas, la posibilidad de aceptar la transmisibilidad de la acción por daño moral así como acabar con una potencial mercantilización de la responsabilidad civil.

\section{REFERENCIAS BIBLIOGRÁFICAS}

Alessandri Rodríguez, Arturo, De La Responsabilidad Extracontractual en el Derecho Civil Chileno. Santiago, Chile: Editorial Jurídica de Chile, 1941.

, Somarriva U., Manuel y Vodanovic H., Antonio, Tratado de Derecho Civil, Tomo I. -6a edición -Santiago, Chile: Editorial Jurídica de Chile, 1998.

Barros Bourie, Enrique, Tratado de responsabilidad extracontractual. Santiago, Chile: Editorial Jurídica de Chile, 2006.

CORRal TAlCiAni, Hernán, Lecciones de responsabilidad civil extracontractual. Santiago, Chile: Editorial Jurídica de Chile, 2003.

DiEz SCHWERTER, José, El daño extracontractual. Santiago, Chile: Editorial Jurídica de Chile, 1997.

Domínguez Águila, Ramón, “Sobre la transmisibilidad de la acción por daño moral” en: Revista Chilena de Derecho, vol. 31, N 3, Santiago, Chile: Pontificia Universidad Católica, 2004.

Domínguez Hidalgo, Carmen, El Daño Moral. Tomo I y II. Santiago, Chile: Editorial Jurídica de Chile, 2000.

"Hacia una uniformidad y trasparencia de la fijación del quantum indemnizatorio", en: Estudios de Derecho Civil II, Santiago: LexisNexis, 2007.

ElORRIAGA DE BONIS, Fabián, "Novedades judiciales en torno al daño moral por repercusión” en Estudios de Derecho Civil II, Santiago: LexisNexis, 2007.

Ramos Pazos, René, De la Responsabilidad Extracontractual. -3a edición-. Santiago: LexisNexis, 2006.

, Sucesión por causa de muerte. Santiago, Chile: Editorial Jurídica de Chile, 2008.

Rodríguez Grez, Pablo, Responsabilidad extracontractual. Santiago, Chile: Editorial Jurídica de Chile, 1999.

SAINZ Moreno, Fernando, “Transmisión hereditaria de la indemnización por daños morales”, en: Revista de Administración Pública, N 124, enero-abril, España, 1991.

Somarriva Undurraga, Manuel, Derecho sucesorio. -3a edición- Santiago, Chile: Editorial Jurídica de Chile, 1981.

SQUella NARDUCCI, Agustín, Introducción al Derecho. Santiago, Chile: Editorial Jurídica de Chile, 2004.

Troncoso Larronde, Hernán, Derecho sucesorio. -4a edición- Concepción, Chile: LexisNexis, 2006.

Vergara Benzanilla, José, "La mercantilización del daño moral”, en: Revista Actualidad Jurídica, Santiago, Chile: Universidad del Desarrollo, 2000.

VIAL DEL RíO, Víctor, Teoría general del acto jurídico. $-5^{\text {a }}$ edición- Santiago, Chile: Editorial Jurídica de Chile, 2003. 